\title{
Powering and Motion Analysis of Twin-Strut Swath Vessels
}

\author{
Y. Gopi Krishna* and Anuj Gupta
}

Department of Naval Architecture \& Offshore Engineering, AMET University, India; gopiyarabala@gmail.com, guptaanuj2@gmail.com

\begin{abstract}
The hydrodynamic characteristics of three different underwater hull forms of the SWATH type are studied based on their powering and motion performance. A SWATH is a twin-hull ship design that holds various advantages over the conventional mono-hulls. The shape of the underwater hull and the struts determine the resistance and motion characteristics of the SWATH. It is important to arrive at an optimum hull shape for maximum performance. SHIPFLOW, a CFD tool developed especially for the marine industry, is used to estimate and compare the resistance and powering characteristics of the three designs. SEDOS, a motion analysis package based on strip theory, is used to estimate the seakeeping characteristics of the hulls. Comment is made on the actual performance on trials when compared against the tank test results, together with the results from various numerical prediction methods.

Based on the results for the three hulls, the most optimum design is found out.
\end{abstract}

Keywords: Resistance, Seakeeping, SEDOS, SHIPFLOW, SWATH

\section{Introduction}

The acronym SWATH stands for Small Water-plane Area Twin Hull. As the name suggests it is an innovative concept of ship of a specific configuration: a twin hull with a minimum cross section at the sea's surface. Thus the ratio of its design water-plane area to hull volumetric displacement is much smaller than that in the case of single hull ships or classical catamarans. The SWATH ship hull consists of two lower hulls (submerged floats), which are connected to the upper hull by means of slender struts on each side of ship plane of symmetry. On the upper deck a superstructure of a size and arrangement suitable to a given ship operational function, is usually provided. Value of design ship draught should ensure an appropriate draught of floats, low design water-plane area and appropriate clearance between water level and lower deck plating.
Some of the features which make SWATH much more attractive to conventional monohull vessels are

i) Small motion even in rough seas

ii) Small wave making resistance in medium to high speed range.

iii) Small speed drop in waves

iv) Good stability

v) Large working deck area

However, the significant drawback of the SWATH vessel is when encountering head-sea at high forward speed. Due to its low stiffness, it has a tendency for large pitch motions. Consequently, this may lead to excessive trim or even deck wetness. This phenomenon will not only degrade the comfortability but also results in structural damage with greater safety risks.

The resistance and motion characteristics of a SWATH is primarily affected by the shape of the underwater hull

*Author for correspondence 
and the struts. It is important to arrive at an optimum hull shape for maximum performance. This project is aimed at identifying the optimum shape from an available set of options. The objective of this project can be achieved either experimentally or through simulation and modelling using Computational Fluid Dynamics (CFD) tools. Experimental results, though more reliable than CFD, can be time consuming and expensive. Also, the primary aim of this study being the comparison of the two hull forms, CFD tools are sufficient enough.

Resistance and powering calculations are carried out on different twin strut SWATH vessels. A commercial CFD tool SHIPFLOW is used for this purpose. The components of resistance are primarily wave resistance and frictional resistance including form resistance. The numerical analysis of the resistance problem combines potential flow solver with RANSE solver for the different regions of the vessel in the flow regions. However, an accurate estimate of the wave resistance can be obtained using a potential flow solver, which optimizes the computational effort and time. The frictional resistance for ship-like forms is usually estimated using ITTC flat plate formula and then multiplying it with the appropriate form factor to consider the increase in resistance due to the increased velocity of flow around the hull. Based on literature, $35 \%$ has been added to the frictional coefficient to account for the form factor.

A motion analysis package namely SEDOS (Soeding, 1988) has been used for obtaining the ship hydrodynamic coefficients for motion prediction. The method is based on strip theory. The program performs calculation for the motion analysis of ship in regular waves and in natural, stationary seas. RAO (Response Amplitude Operator) of all the six modes of ship motions at various speeds are obtained.

Seren (1983) and Kennell ${ }^{5}$ presented that the major attribute of SWATH vessel is considered to offer good ride quality exceeding compared with a monohull vessel of equivalent displacement under rough condition. Kennell ${ }^{5}$, McCreight ${ }^{7}$, and Fang ${ }^{4}$ stated that the better seakeeping performance of the SWATH vessel concept is associated with its small waterplane concept. Those advantages were naturally provided by a stable platform in seaway and their features indicate significantly low wave excitation forces, greatly reduced deck motions exhibited while at rest or underway, lower accelerations for given amplitude of motion, eliminate the seasickness, and give the vessel mobility comparable to mono-hulls.
Djatmiko (2004), Dubrovskiy, and Lyakhoviyskiy ${ }^{3}$, $\mathrm{McCreight}^{7}$ and Clark, et $\mathrm{al}^{2}$ explained in the view of safety aspect, the significant drawback accompanied with low waterplane area. This feature has caused the SWATH vessel to have more sensitivity of draught to changes in weight during design and operation. Also, the low waterplane area brings about reduction in the moment to change trim, which also means low hydrostatic restoring moment, hence making the vessel vulnerable towards pitch instabilities due to dropped or low restoring pitch moment resulted due to increase in speed.

Tamotsu ${ }^{10}$ has done a critical review of the SWATH vessels, identifying the effect of factors such as Under water hull form, strut, fin automatic control, propulsion systems etc. on the performance of the vessel.

\section{SWATH Particulars}

A total of three different underwater hull shapes are studied based on their powering and motion performances. For the purpose of identification the hulls are named as SWATH-A, SWATH-B, and SWATH-C. The particulars of each hull are explained in the following sections with corresponding Figures.

\subsection{SWATH-A}

The main characteristics of the hull, SWATH-A are summarized in the Table 1. (Figures 1-3)

Table 1. Particulars of SWATH-A

\begin{tabular}{lc}
\hline & SWATH-A \\
\hline LWL(m) & 20.88 \\
Beam (m) & 10.524 \\
Draft(m) & 2.5 \\
Displacement (m3) & 115.24 \\
Surface Area(m2) & 251.77 \\
Service Speed (knots) & 12 \\
Max Strut Width(m) & 1.14 \\
Max Underwater Hull Breadth(m) & 1.88 \\
Strut Length Fwd(m) & 8.28 \\
Strut Length Aft(m) & 10.6 \\
Distance from the top surface of underwater & 0.63 \\
body to WL, at midship(m) & 2 \\
Space Between the struts(m) & 4.32 \\
Distance between CL to mid of the hull (m) &
\end{tabular}




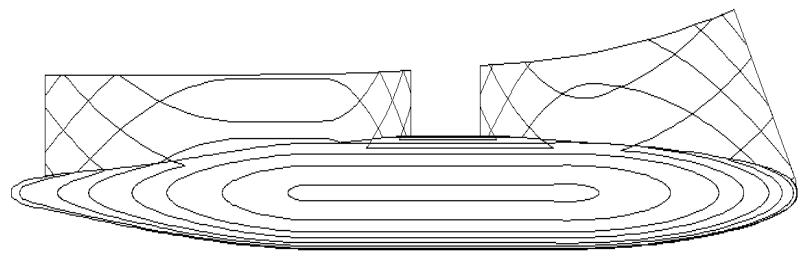

Figure 1. Profile view of SWATH-A.

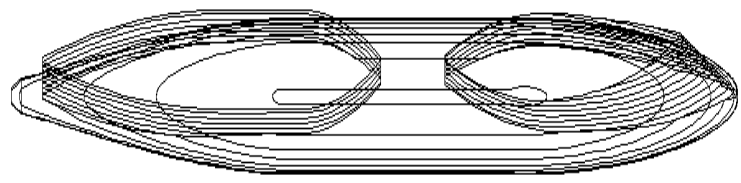

Figure 2. Plan view of SWATH-A.

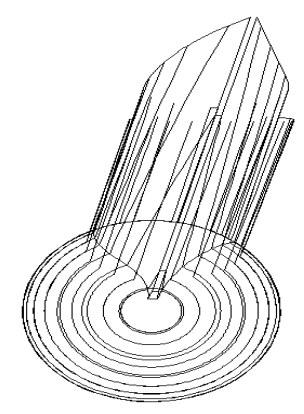

Figure 3. Body view of SWATH-A.

\subsection{SWATH-B}

The main characteristics of the hull, SWATH-B are summarized in the Table 2. (Figures 4-6)

\subsection{SWATH-C}

The main characteristics of the hull, SWATH-C are summarized in the Table 3. (Figures 7-9)

\section{SHIPFLOW Results}

All three hulls were run in SHIPFLOW for various Froude numbers. The results obtained are presented in the following sections.

\subsection{SWATH-A}

The wave making resistance coefficient $\mathrm{Cw}$ is evaluated using SHIPFLOW. ITTC formula is used to compute frictional resistance coefficient $\mathrm{Cf}$ and a form factor $1+\mathrm{k}=$ 1.35 is used. The results are given in Table 4. Resistance
Table 2. Particulars of SWATH-B

\begin{tabular}{lc}
\hline & SWATH-B \\
\hline LWL(m) & 20.88 \\
Beam (m) & 10.524 \\
Draft $(\mathrm{m})$ & 2.5 \\
Displacement (m3) & 119.73 \\
Surface Area(m2) & 256.3 \\
Service Speed (knots) & 12 \\
Max Strut Width(m) & 1.14 \\
Max Underwater Hull Breadth(m) & 1.88 \\
Strut Length Fwd(m) & 8.28 \\
Strut Length Aft(m) & 10.6 \\
Distance from the top surface of underwater & 0.63 \\
body to WL, at midship(m) & 2 \\
Space Between the struts(m) & 4.32 \\
Distance between CL to mid of the hull (m)
\end{tabular}

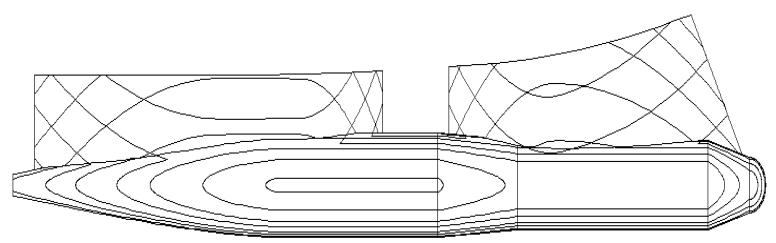

Figure 4. Profile view of SWATH-B.

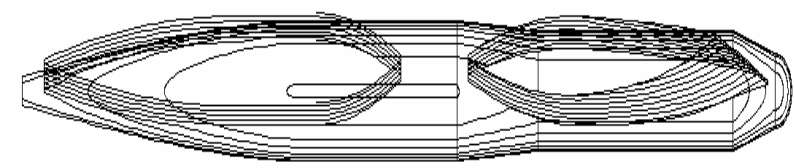

Figure 5. Plan view of SWATH-B.

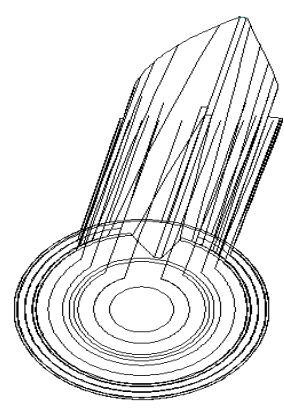

Figure 6. Body view of SWATH-B. 
Table 3. Particulars of SWATH-C

\begin{tabular}{lc}
\hline & SWATH-C \\
\hline LWL(m) & 22.24 \\
Beam (m) & 10.65 \\
Draft(m) & 2.6 \\
Displacement (m3) & 133.67 \\
Surface Area(m2) & 276.87 \\
Service Speed (knots) & 12 \\
Max Strut Width(m) & 1.19 \\
Max Underwater Hull Breadth(m) & 2 \\
Strut Length Fwd(m) & 9.5 \\
Strut Length Aft(m) & 9.76 \\
Distance from the top surface of underwater & 0.85 \\
body to WL, at midship(m) & 3 \\
Space Between the struts(m) & 4.33 \\
Distance between CL to mid of the hull (m) &
\end{tabular}

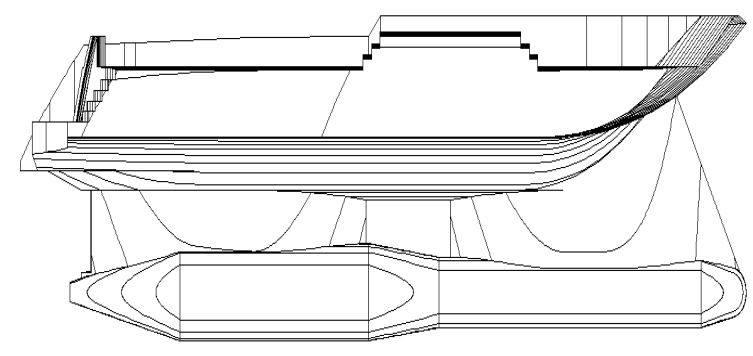

Figure 7. Profile view of SWATH-C.

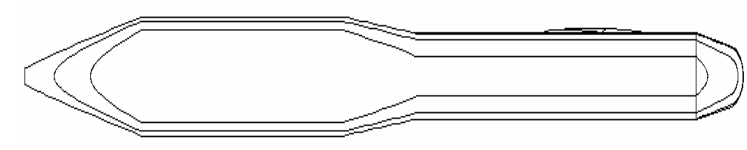

Figure 8. Plan view of SWATH-C underwater hull.

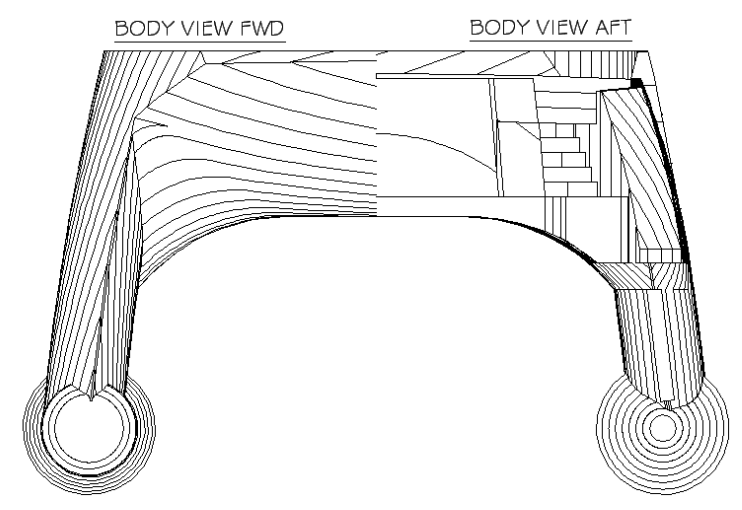

Figure 9. Body view of SWATH-C. coefficients and Effective Power requirement at various Froude numbers are plotted in Figure 10 and Figure 11 respectively.

\subsection{SWATH-B}

The wave making resistance coefficient $\mathrm{Cw}$ is evaluated using SHIPFLOW. ITTC formula is used to compute frictional resistance coefficient, $\mathrm{Cf}$ and a form factor $1+\mathrm{k}$ $=1.35$ is used. The results are given in Table 5 .

Resistance coefficients and Effective Power requirement at various Froude numbers are plotted in Figure 12 and Figure 13 respectively.

\subsection{SWATH-C}

The wave making resistance coefficient $\mathrm{Cw}$ is evaluated using SHIPFLOW. ITTC formula is used to compute frictional resistance coefficient, Cf and a form factor $1+\mathrm{k}$ $=1.35$ is used. The results are given in Table 6 . Resistance coefficients as well as Effective power requirement at various Froude numbers are plotted in Figure 14 and Figure 15 respectively.

\section{Experimental Results}

Resistance of one of the three hulls i.e. SWATH-C, is estimated experimentally also in order to validate the SHIPFLOW results. A 1:10 model was used for this purpose (Figure 16). The values obtained are plotted along with the numerical results from SHIPFLOW in Figure 17. The trends of both experimental and numerical results are matching quite accurately. However, the SHIPFLOW results are seen to be much higher than the experimental values. Similar observations were made by M. Salas et al. in their paper titled 'Experimental and CFD Resistance Calculation of a Small Fast Catamaran'. The SHIPFLOW results were found to be much higher than experimental results in the range $0.2<\mathrm{Fn}<0.5$ though the trend remained the same. Assuming that the effect of numerical errors will be same on all three SWATH hulls, the fact that the trend is captured accurately by SHIPFLOW is enough for the purpose of comparing the powering characteristics of the three hulls.

\subsection{Discussion and Comparison}

The three SWATH hulls being of different displacements, effective power per unit displacement is used as a parameter 
Table 4. Powering estimation of SWATH-A

\begin{tabular}{lcccccccc}
\hline Fn & $\mathrm{V}(\mathrm{m} / \mathrm{s})$ & $\mathrm{Rn}$ & $\mathrm{Cw}$ & $\mathrm{Cf}$ & $(\mathbf{1 + k}) \mathrm{Cf}$ & $\mathrm{Ct}$ & $\mathrm{Rt}(\mathrm{kN})$ & $\mathrm{PE}(\mathrm{kW})$ \\
\hline 0.20 & 3.00 & $6.86 \mathrm{E}+07$ & $1.92 \mathrm{E}-02$ & 0.002202 & 0.0030 & 0.0222 & 25.96 & 77.81 \\
0.25 & 3.75 & $8.57 \mathrm{E}+07$ & $1.49 \mathrm{E}-02$ & 0.002131 & 0.0029 & 0.0178 & 32.58 & 122.06 \\
0.30 & 4.50 & $1.03 \mathrm{E}+08$ & $1.86 \mathrm{E}-02$ & 0.002075 & 0.0028 & 0.0214 & 56.51 & 254.03 \\
0.35 & 5.24 & $1.20 \mathrm{E}+08$ & $9.97 \mathrm{E}-03$ & 0.002029 & 0.0027 & 0.0127 & 45.61 & 239.22 \\
0.40 & 5.99 & $1.37 \mathrm{E}+08$ & $1.07 \mathrm{E}-02$ & 0.001991 & 0.0027 & 0.0134 & 62.63 & 375.36 \\
0.45 & 6.74 & $1.54 \mathrm{E}+08$ & $1.18 \mathrm{E}-02$ & 0.001958 & 0.0026 & 0.0144 & 85.68 & 577.72 \\
0.50 & 7.49 & $1.71 \mathrm{E}+08$ & $1.12 \mathrm{E}-02$ & 0.00193 & 0.0026 & 0.0138 & 101.10 & 757.44 \\
0.55 & 8.24 & $1.89 \mathrm{E}+08$ & $1.00 \mathrm{E}-02$ & 0.001904 & 0.0026 & 0.0126 & 111.39 & 918.01 \\
\hline
\end{tabular}

to compare their performance as presented in Figure 18. It is observed that SWATH-B fares better than its counter parts at all speeds. SWATH-A, though it follows the trend of SWATH-B, has a slightly higher power requirement through out the service range. Advantage of SWATH-B over SWATH-A could be because of its bulbous bow type front end. SWATH-C has an altogether different trend compared to the other two, the prominent feature being a hump around Froude Number $=0.325$.

Surprisingly, SWATH-C, though a twin strut, demi-hull vessel, shows similarity to quad hulls, also known as SLICE hulls for Fn $<0.4$ and similar to SWATH A \& B for higher Froude numbers as shown in Figure 19. The values for SLICE hulls were obtained from the thesis 'Comparative study on Powering and Motion aspects of SLICE and SWATH hulls', by Pavan Kumar, Dept of Ocean Engineering, IIT-M. The observed deviation of trend for SWATH-C from the other two is probably because of its higher spacing between the struts.

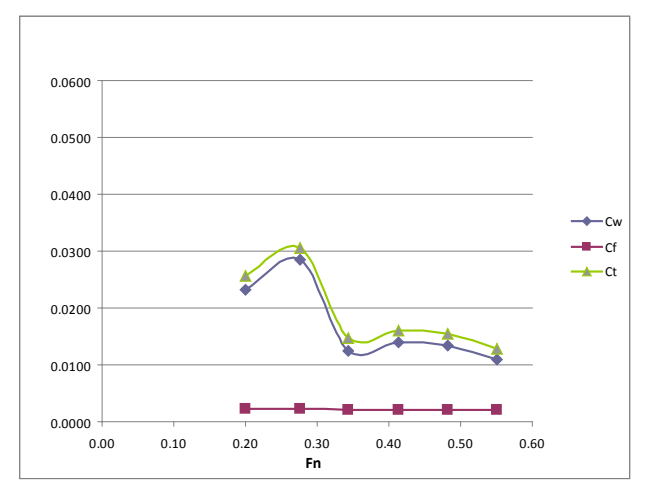

Figure 10. Resistance coefficients Vs Fn for SWATH-A.
To further study the effect of struts on resistance, a modified version of SWATH-C was run in SHIPFLOW in the range $0<\mathrm{Fn}<0.45$, the difference being that the twin strut was converted to a single unbroken strut from bow to aft. The results obtained are given in Figure 20. It is seen that converting twin strut into single strut has resulted in a large reduction in powering requirements of the SWATH-C making it closer and better than SWATH-B.

\section{Motion Predictions}

The CFD software SEDOS was used to analyze the motion characteristics of the three SWATHs.

The motion output from SEDOS is non-dimensionalized RAOs (Response Amplitude Operator) as given below.

For Surge, Sway and Heave,

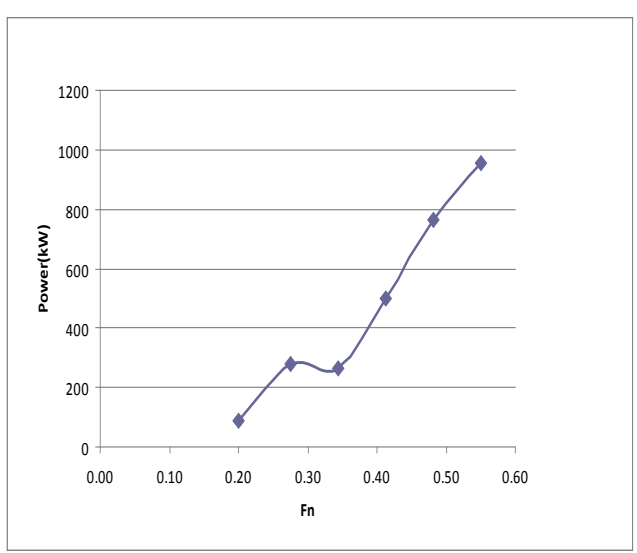

Figure 11. Effective power requirement Vs Fn for SWATH-A. 
Table 5. Powering estimation of SWATH-B

\begin{tabular}{lcccccccc}
\hline Fn & $\mathrm{V}(\mathrm{m} / \mathrm{s})$ & $\mathrm{Rn}$ & $\mathrm{Cw}$ & $\mathrm{Cf}$ & $(1+\mathrm{k}) \mathrm{Cf}$ & $\mathrm{Ct}$ & $\mathrm{Rt}(\mathrm{kN})$ & $\mathrm{PE}(\mathrm{kW})$ \\
\hline 0.20 & 2.99 & $6.80 \mathrm{E}+07$ & 0.0233 & 0.002205 & 0.0030 & 0.0263 & 29.83 & 89.14 \\
0.28 & 4.12 & $9.37 \mathrm{E}+07$ & 0.0284 & 0.002103 & 0.0028 & 0.0312 & 67.34 & 277.29 \\
0.34 & 5.14 & $1.17 \mathrm{E}+08$ & 0.0125 & 0.002037 & 0.0027 & 0.0152 & 51.22 & 263.24 \\
0.41 & 6.18 & $1.41 \mathrm{E}+08$ & 0.0140 & 0.001984 & 0.0027 & 0.0167 & 80.80 & 499.07 \\
0.48 & 7.21 & $1.64 \mathrm{E}+08$ & 0.0135 & 0.001942 & 0.0026 & 0.0161 & 106.30 & 765.99 \\
0.55 & 8.24 & $1.87 \mathrm{E}+08$ & 0.0109 & 0.001906 & 0.0026 & 0.0134 & 115.92 & 954.63 \\
\hline
\end{tabular}

RAO $=$ Motion Amplitude/ Wave Amplitude

For Roll, Pitch and Yaw,

$\mathrm{RAO}=$ Motion Amplitude/(Wave number * Wave Amplitude)

\subsection{SEDOS Results}

All three hulls were run in SEDOS for various speeds and various heading angles. The output obtained for all six degrees of motions are given in the following sections. For each motion, only the output at the most relevant wave angle is given.

\subsubsection{Heave}

From the results obtained, heave is most significant when the waves are at 180 degrees i.e. Head Sea condition. The

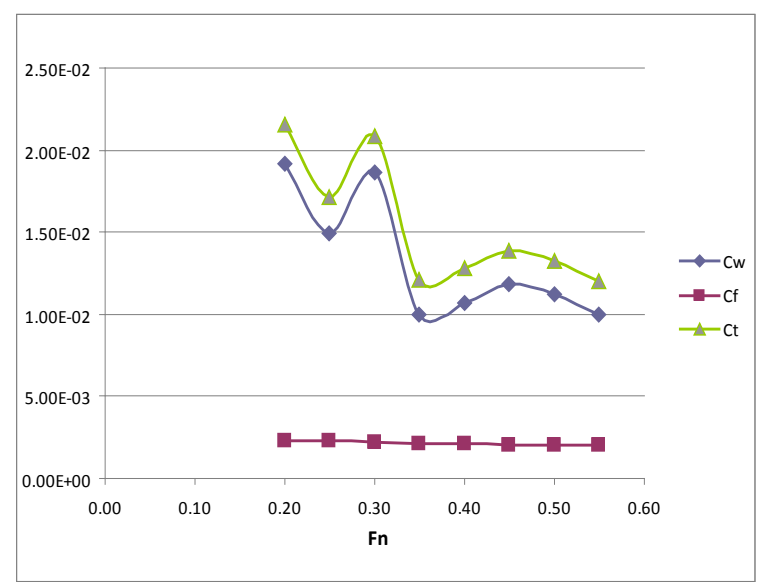

Figure 12. Resistance coefficients Vs Fn for SWATH-B.
Heave RAO is plotted against various Lw/L (Length of wave divided by Length of Vessel) for various speeds. (Figures 21-23).

\subsubsection{Pitch}

From the results obtained, pitch is most significant when the waves are at Head Sea condition. Pitch RAO is plotted against various Lw/L (Length of wave divided by Length of Vessel) for various speeds. (Figures 24-26).

\subsubsection{Roll}

From the results obtained, roll is most significant when the waves are at 90 degrees (Beam Sea condition). Roll RAO is plotted against various Lw/L (Length of wave divided by Length of Vessel) for various speeds. (Figures 27-29).

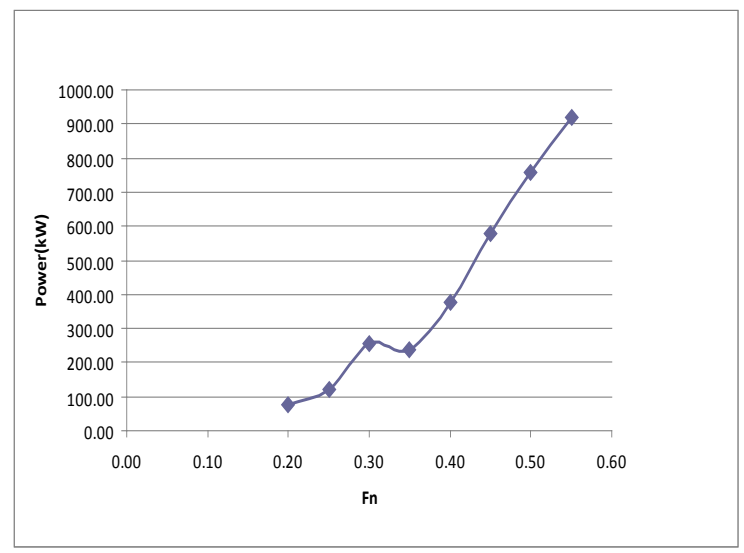

Figure 13. Effective power requirement Vs Fn for SWATH-B. 
Table 6. Powering estimation of SWATH-C

\begin{tabular}{lcccccccc}
\hline Fn & Vm/s & Rn & Cw & Cf & $(1+k) C f$ & Ct & Rt $(\mathrm{kN})$ & PE $(\mathrm{kW})$ \\
\hline 0.2 & 3.122 & $6.96 \mathrm{E}+07$ & $2.07 \mathrm{E}-02$ & 0.002197 & 0.002966 & 0.0236 & 32.3970 & 101.13 \\
0.25 & 3.902 & $8.70 \mathrm{E}+07$ & $1.54 \mathrm{E}-02$ & 0.002126 & 0.00287 & 0.0183 & 39.1226 & 152.66 \\
0.275 & 4.292 & $9.57 \mathrm{E}+07$ & $2.87 \mathrm{E}-02$ & 0.002097 & 0.00283 & 0.0315 & 81.7663 & 350.96 \\
0.3 & 4.682 & $1.04 \mathrm{E}+08$ & $3.49 \mathrm{E}-02$ & 0.00207 & 0.002795 & 0.0377 & 116.3834 & 544.96 \\
0.325 & 5.073 & $1.13 \mathrm{E}+08$ & $3.14 \mathrm{E}-02$ & 0.002047 & 0.002763 & 0.0342 & 123.8531 & 628.26 \\
0.35 & 5.463 & $1.22 \mathrm{E}+08$ & $2.46 \mathrm{E}-02$ & 0.002025 & 0.002734 & 0.0274 & 114.9597 & 628.00 \\
0.375 & 5.853 & $1.31 \mathrm{E}+08$ & $1.73 \mathrm{E}-02$ & 0.002005 & 0.002707 & 0.0200 & 96.4827 & 564.72 \\
0.4 & 6.243 & $1.39 \mathrm{E}+08$ & $1.55 \mathrm{E}-02$ & 0.001987 & 0.002682 & 0.0182 & 99.7344 & 622.66 \\
0.45 & 7.024 & $1.57 \mathrm{E}+08$ & $1.16 \mathrm{E}-02$ & 0.001954 & 0.002638 & 0.0142 & 98.8891 & 694.56 \\
0.5 & 7.804 & $1.74 \mathrm{E}+08$ & $1.15 \mathrm{E}-02$ & 0.001926 & 0.0026 & 0.0141 & 120.9842 & 944.16 \\
0.55 & 8.584 & $1.91 \mathrm{E}+08$ & $9.65 \mathrm{E}-03$ & 0.0019 & 0.002566 & 0.0122 & 126.6955 & 1087.61 \\
\hline
\end{tabular}

\subsubsection{Surge}

From the results obtained, surge is most significant when the waves are at 0 degrees (Following Sea condition). Surge RAO is plotted against various Lw/L (Length of wave divided by Length of Vessel) for various speeds (Figures 30-32).

\subsubsection{Sway}

From the results obtained, sway is most significant when the waves are at 45 degrees to the SWATH's heading. Sway RAO is plotted against various $\mathrm{Lw} / \mathrm{L}$ (Length of wave divided by Length of Vessel) for various speeds (Figures 33-35).

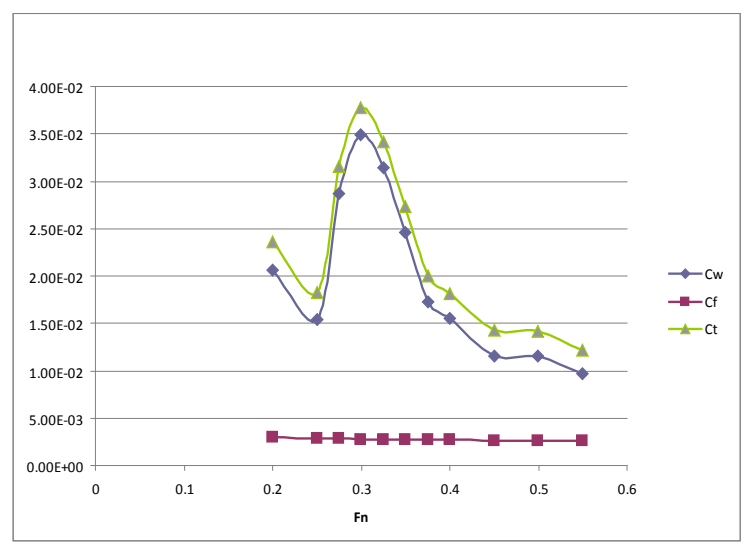

Figure 14. Resistance coefficients Vs Fn for SWATH-C.

\subsubsection{Yaw}

From the results obtained, yaw is most significant when the waves are at 45 degrees to the SWATH's heading. Yaw RAO is plotted against various Lw/L (Length of wave divided by Length of Vessel) for various speeds Figures 36-38).

\subsection{Discussion and Comparison}

SWATH-A and SWATH-B follows almost similar trend in all motions. For Heave motion, SWATH- C has a lower response compared to the other two SWATHs. Comparison between the three hulls is shown in Figure 39 at 12 knots vessel speed and waves at head sea condition.

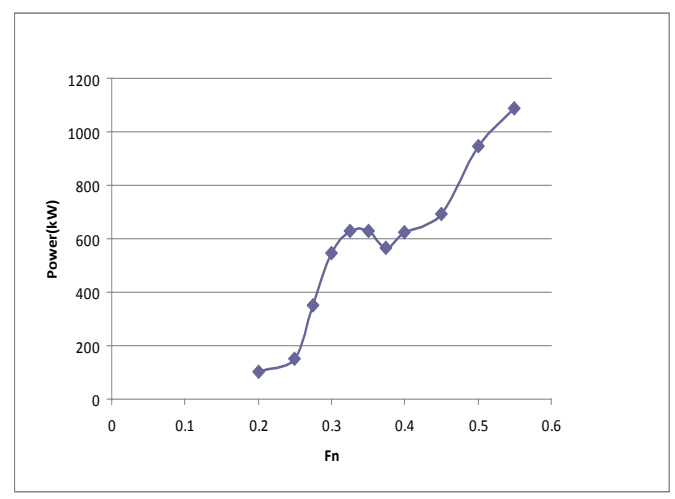

Figure 15. Effective power requirement Vs Fn for SWATH-C. 


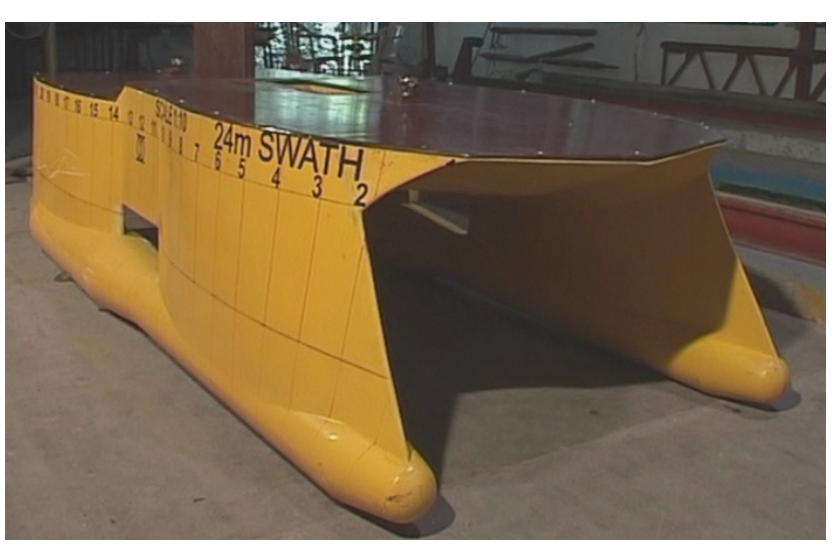

Figure 16. Model used for experimental determination of resistance

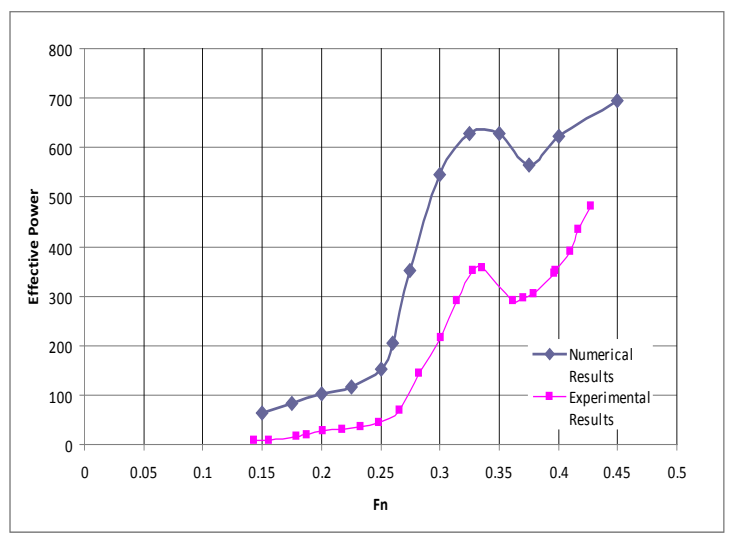

Figure 17. Comparison of numerical and experimental results for SWATH-C.

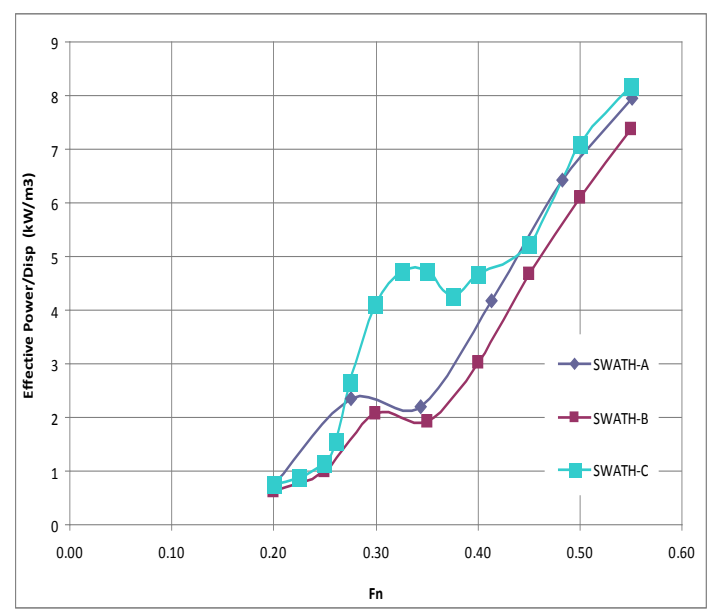

Figure 18. Comparison of effective power per unit displacement.

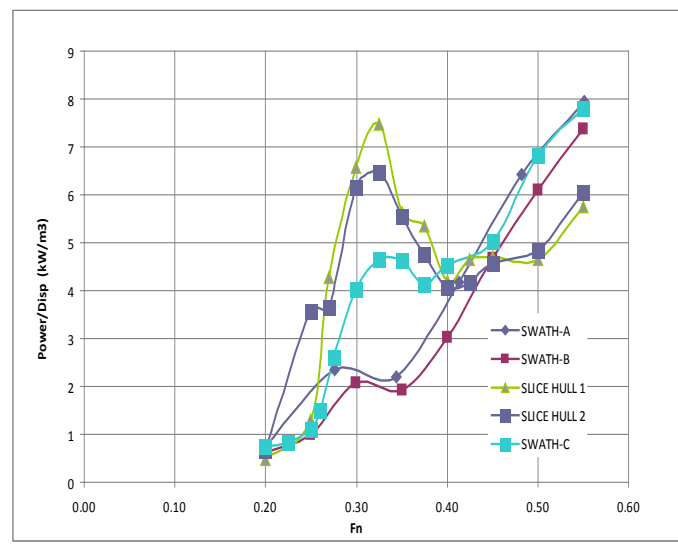

Figure 19. Comparison of effective power of SWATH and SLICE.

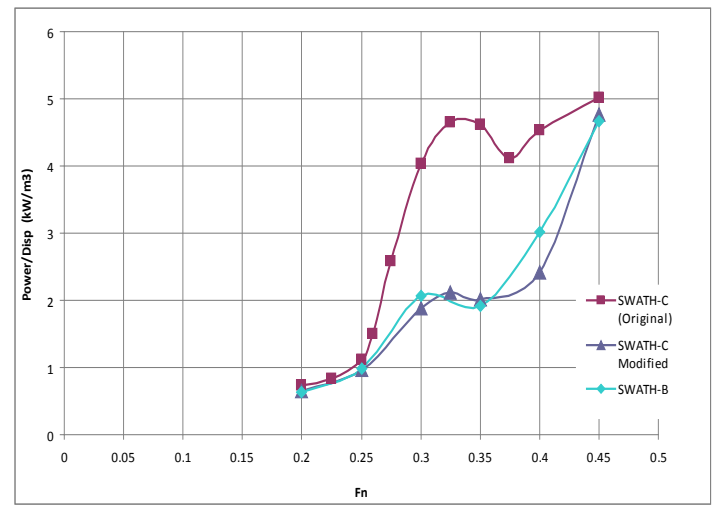

Figure 20. Comparison of a modified design to the original SWATHs.

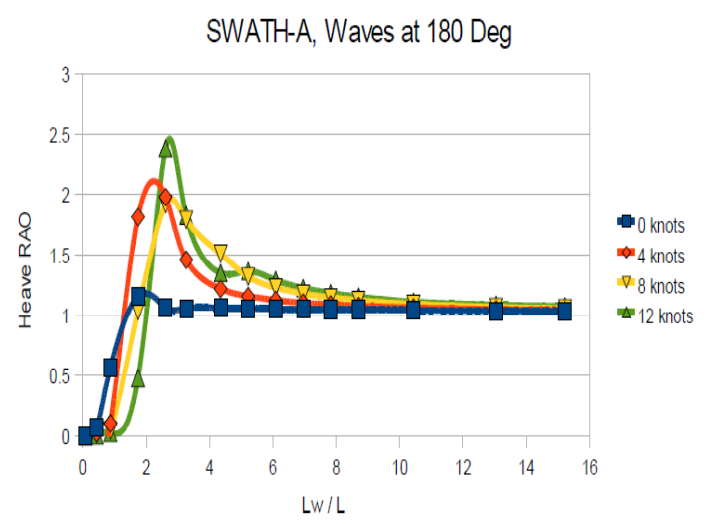

Figure 21. Heave RAO for Swath-A at wave angle $=180$ Deg. 
SWATH-B, Waves at 180 Deg

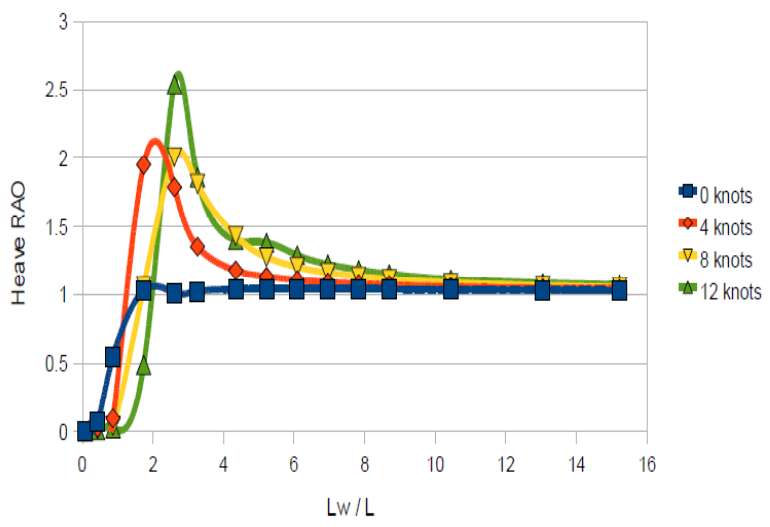

Figure 22. Heave RAO for Swath-B at wave angle $=180$ Deg.

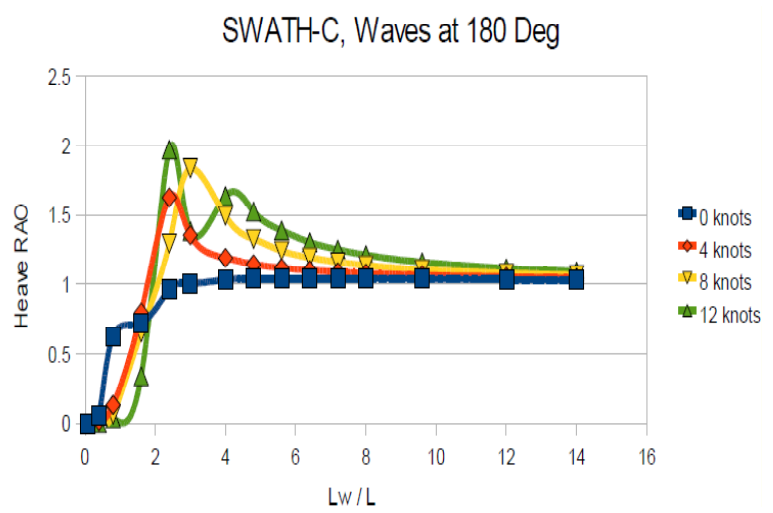

Figure 23. Heave RAO for Swath-C at wave angle $=180$ Deg.

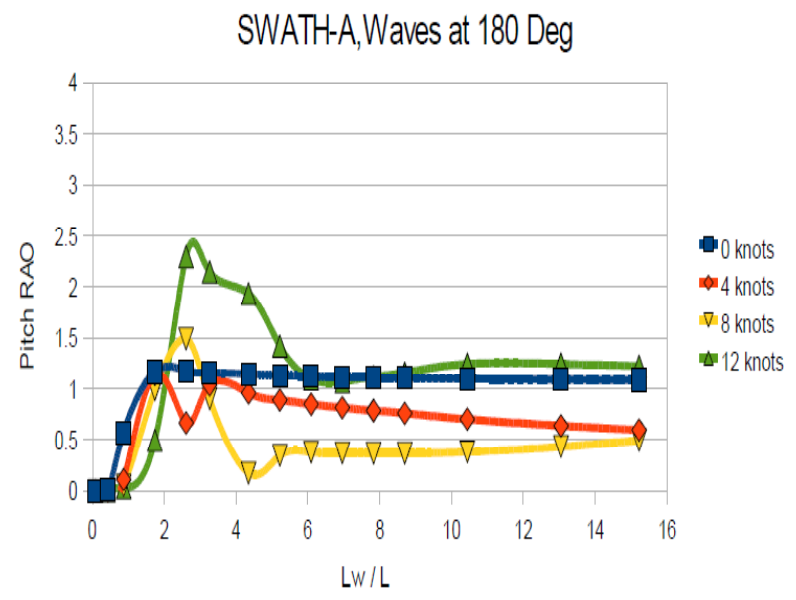

Figure 24. Pitch RAO for Swath-A at wave angle $=180$ Deg.

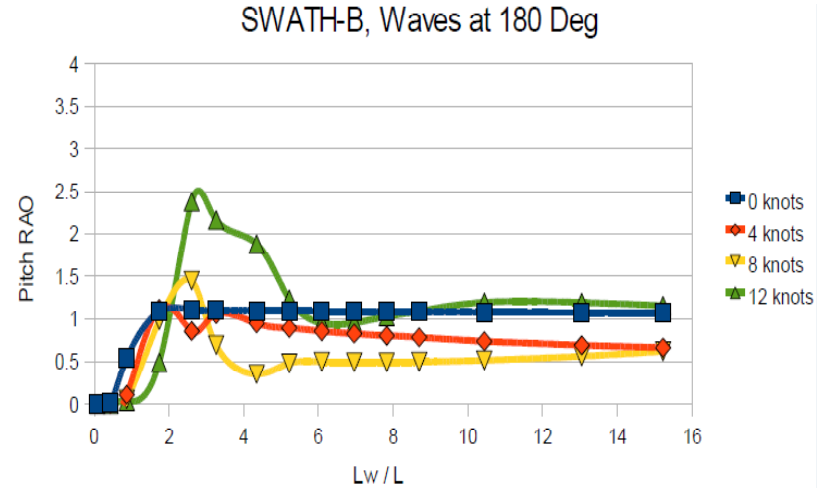

Figure 25. Pitch RAO for Swath-B at wave angle $=180$ Deg.

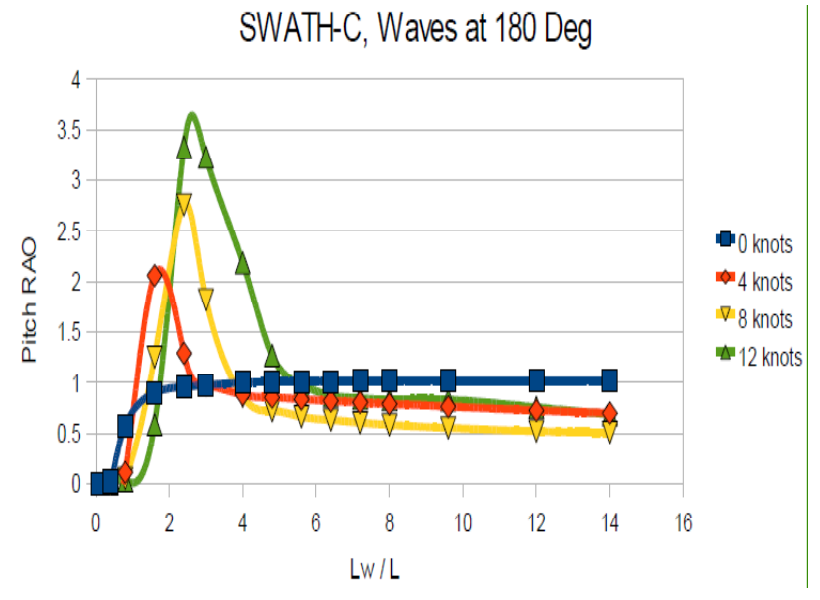

Figure 26. Pitch RAO for Swath-C at wave angle $=180$ Deg.

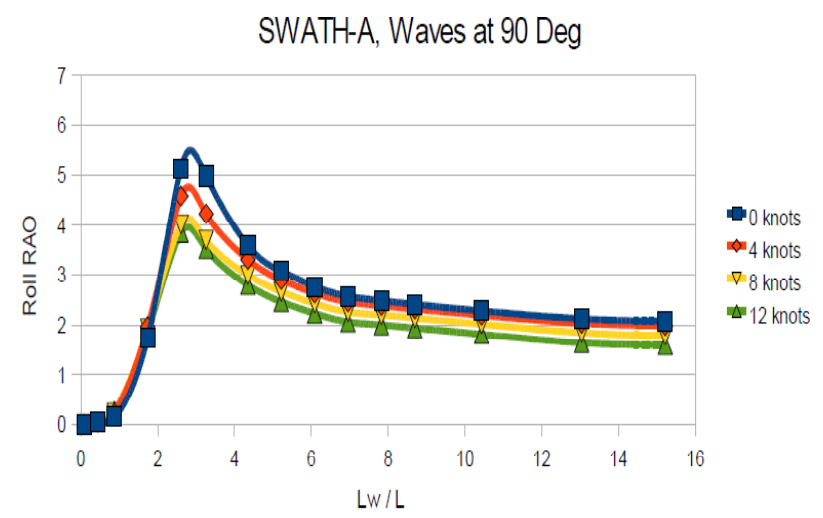

Figure 27. Roll RAO for Swath-A at wave angle $=90 \mathrm{Deg}$. 
SWATH-B, Waves at 90 Deg

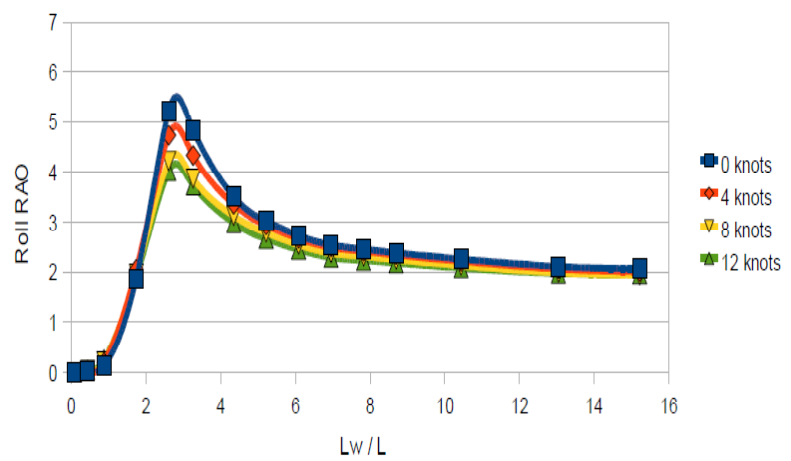

Figure 28. Roll RAO for Swath-B at wave angle $=90 \mathrm{Deg}$.

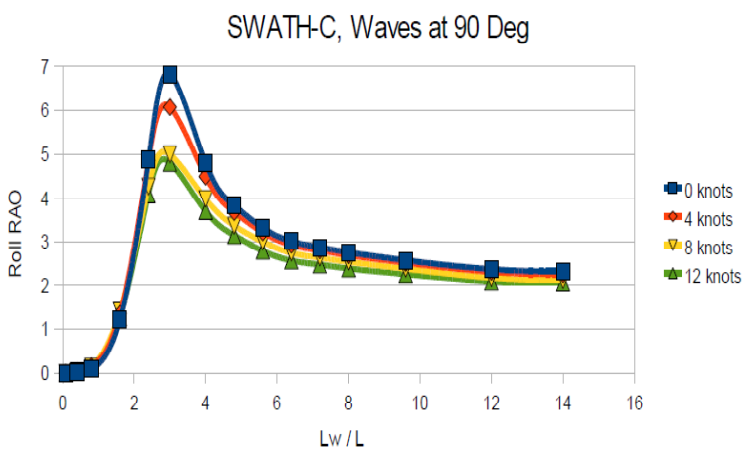

Figure 29. Roll RAO for Swath-C at wave angle $=90 \mathrm{Deg}$.

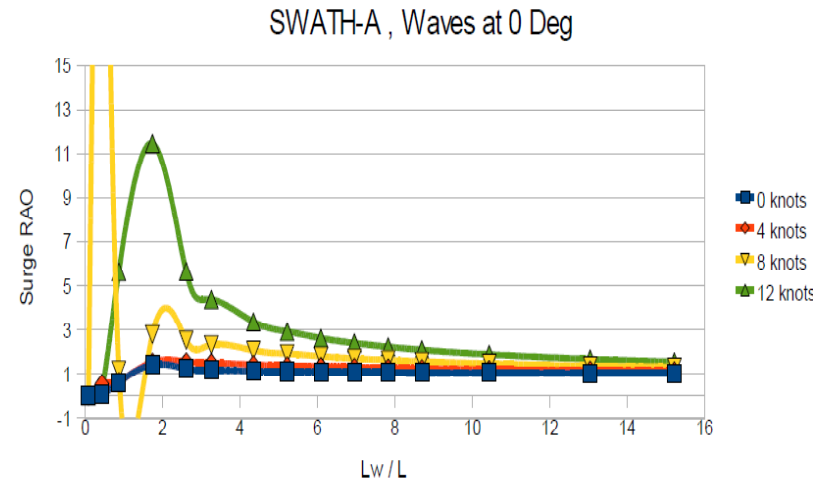

Figure 30. Surge RAO for Swath-A at wave angle $=0$ Deg.

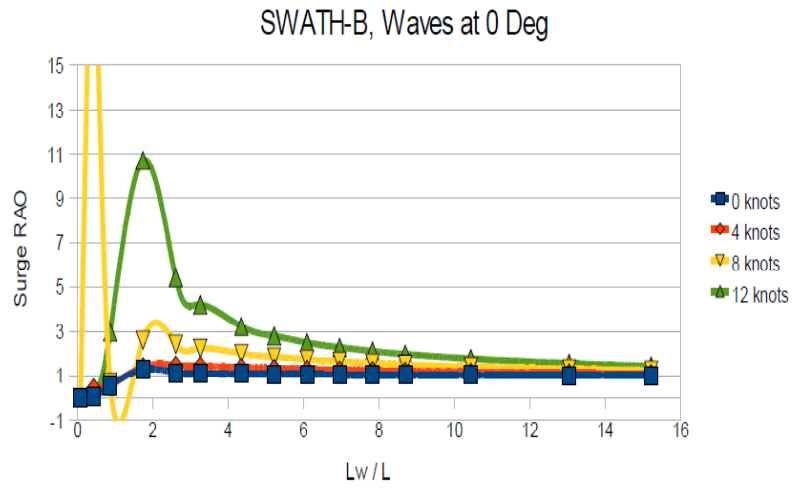

Figure 31. Surge RAO for Swath-B at wave angle $=0$ Deg.

SWATH-C, Waves at 0 Deg

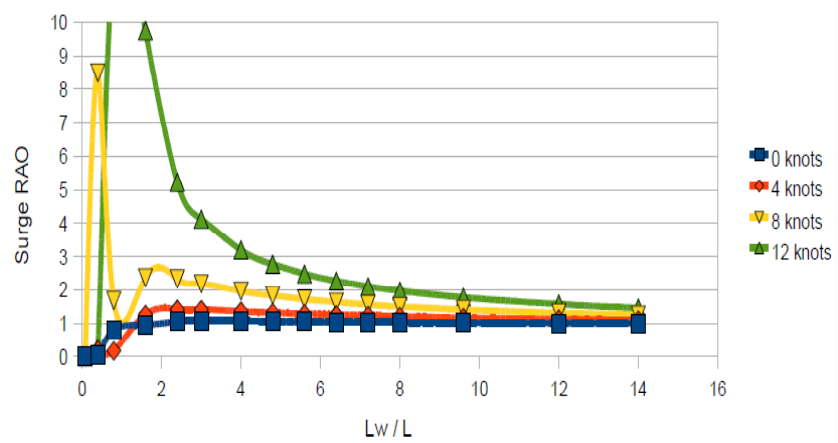

Figure 32. Surge RAO for Swath-C at wave angle $=0$ Deg.

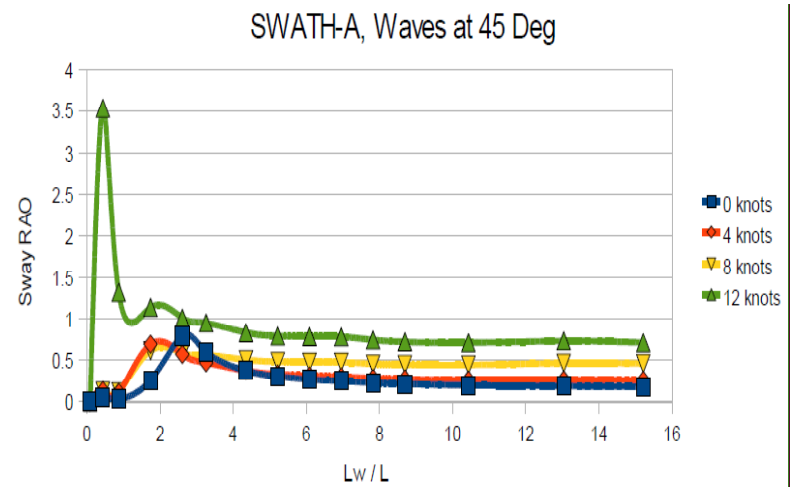

Figure 33. Sway RAO for Swath-A at wave angle $=45$ Deg. 


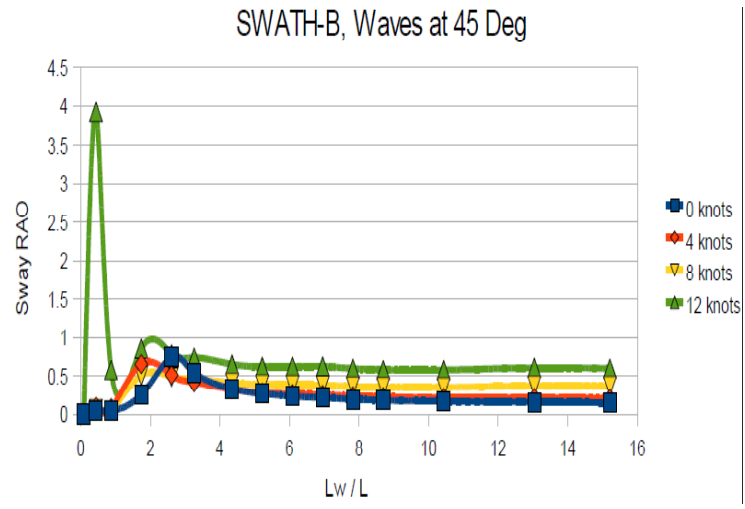

Figure 34. Sway RAO for Swath-B at wave angle $=45$ Deg.

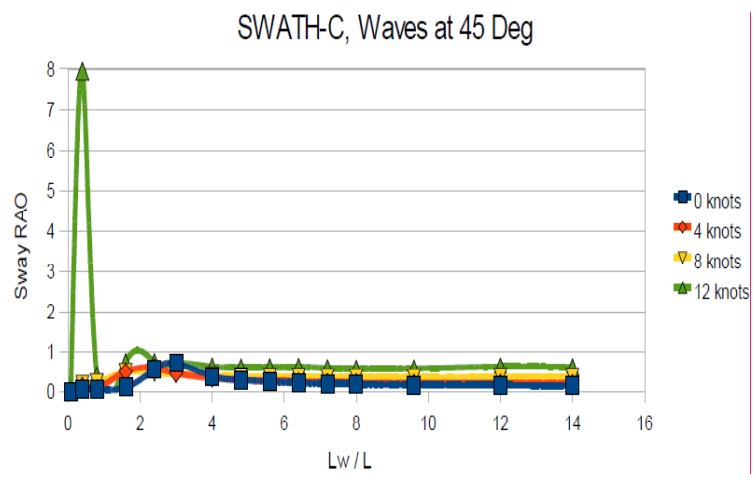

Figure 35. Sway RAO for Swath-C at wave angle $=45$ Deg.

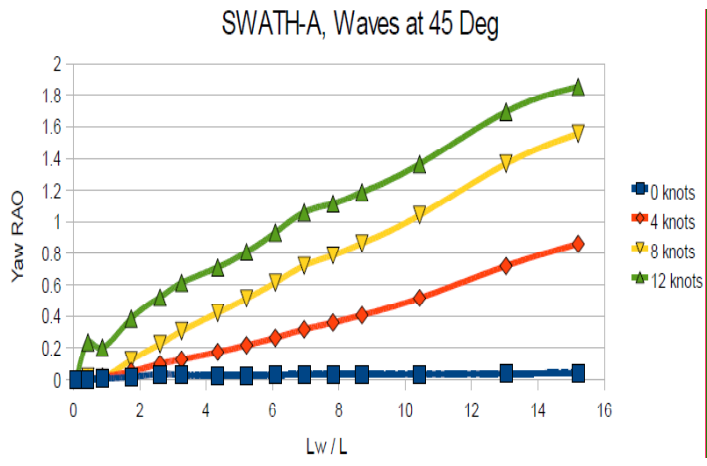

Figure 36. Yaw RAO for Swath-A at wave angle $=45$ Deg.

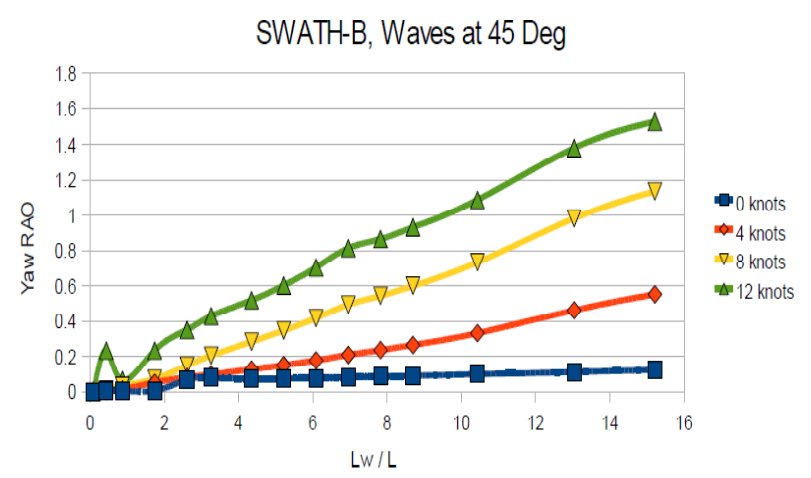

Figure 37. Sway RAO for Swath-B at wave angle $=45$ Deg.

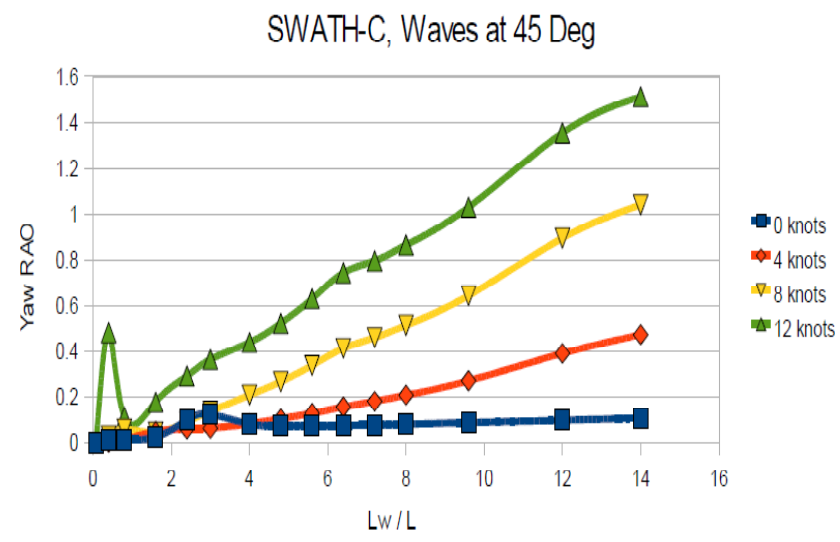

Figure 38. Sway RAO for Swath-C at wave angle $=45$ Deg.

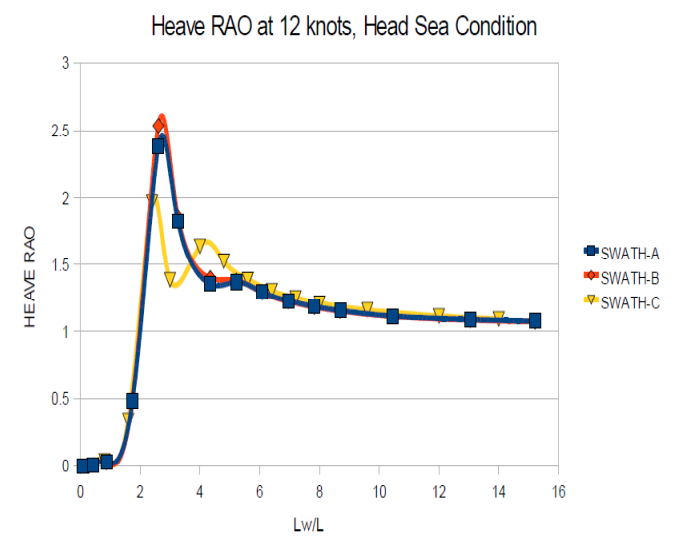

Figure 39. Comparison of Heave RAO of the three SWATH hulls. 
However, SWATH-C has a pitch response which is about 40-50 \% higher compared to that of other two at various speeds. A comparison of the pitch RAO at a vessel speed of 12 knots, and waves at head sea condition, is shown in Figure 40.

Roll RAO of all three SWATH vessels were maximum in a beam sea at a zero vessel speed. The performance of SWATH-A and SWATH-B are similar at all wave lengths. However, SWATH-C's resonance peak is higher by about 20-25\%. A comparison between the three is presented in Figure 41 .

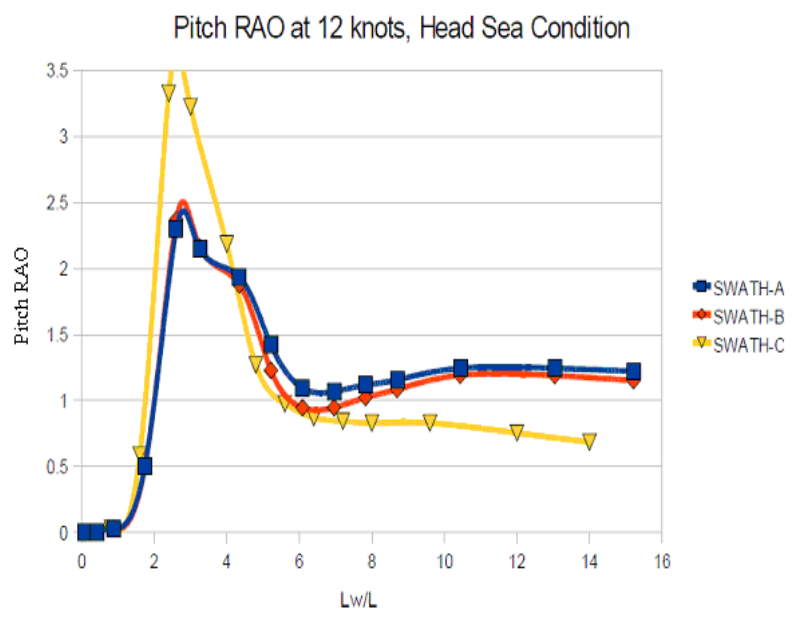

Figure 40. Comparison of Pitch RAO of the three SWATH hulls.

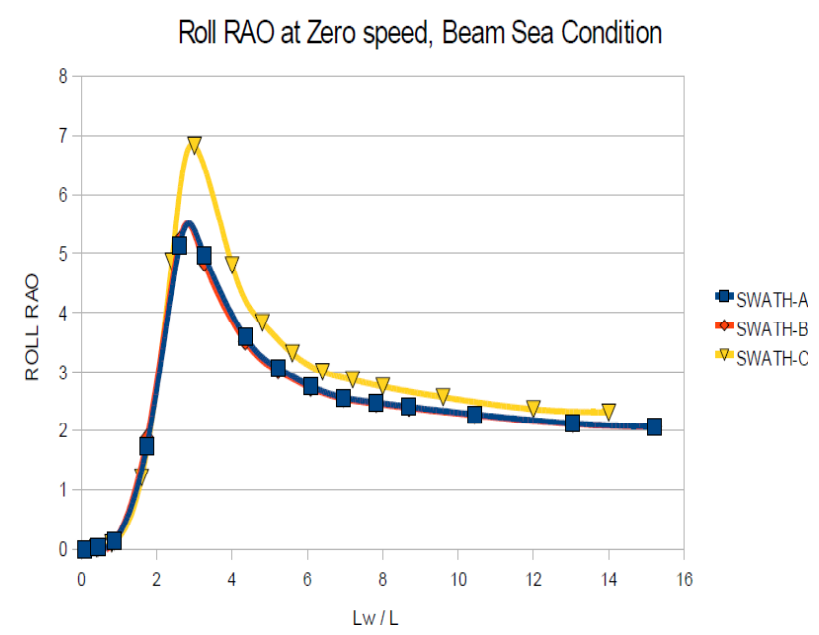

Figure 41. Comparison of Roll RAO of the three SWATH hulls.
The Surge RAO given by SEDOS is extremely high in following sea conditions for vessel speeds above 8 knots. This is due to the instability of strip theory when the encountering frequency of the vessel becomes negative, which is the case here ${ }^{6,7}$.

The Sway RAO of all three SWATHs show a resonance peak for a vessel speed of 12 knots at Lw/L $=0.44$. But the reliability of this prediction is doubtful because of the negative encountering frequency in this situation.

The Yaw RAO is seen to have no resonance peaks and increases gradually with wave length except for peaks occurring at a velocity of 12 knots at $\mathrm{Lw} / \mathrm{L}=0.44$ (Figures 36-38). These peaks may have occurred due to the strip theory instabilities in negative encountering frequencies.

\section{Conclusions}

- All three SWATH hulls were studied using SHIPFLOW for their resistance characteristics and SEDOS for their motion characteristics.

- SWATH-B has lower power requirements at all vessel speeds compared to SWATH-A and SWATH-C.

- The resistance trend of SWATH-C is seen be following a trend similar to SLICE hulls for Froude numbers less than 0.425 and that of twin strut SWATH hulls for higher Froude numbers. This different trend could be due to the increased strut spacing of SWATH-C.

- A modified design of SWATH-C, by making the twin strut into a single strut, was found to have better powering characteristics than even SWATH-B.

- SWATH-A and SWATH-B have almost similar motion responses, particularly in Heave, Pitch and Roll. SWATH- C has a heave response lower than the other two vessels. However its resonant pitch and roll responses are higher than SWATH-A and SWATH-B by about $45 \%$ and $25 \%$ respectively.

- Taking into consideration both powering and motion aspects, SWATH-B seems to be the best option out of the three vessels.

\section{References}

1. Chan HS. Prediction of motion and wave loads of twin-hull ships. Marine Structur. 1993; 6 (1): 75-102. 
2. Clark AC, et al. On the design and evaluation of control system for swath ship. Proceeding, International Conference on Modeling and Control Marine Craft; Exeter, UK: Elsevier Science Publishers Ltd.; 1990. p. 53-74.

3. Dubrovskiy VA, Lyakhoviyskiy A. Multi-hull ships. United States of America, USA: Backbone Publishing Company; 2001. p. 225.

4. Fang MC. The Motions of SWATH ships in Waves. J Ship Res. 1988; 32: 238-45.

5. Kennell C. SWATH ships, USA: The Society of Naval Architects and Marine Engineers. Tech Res Bull. 1992; 7-5.

6. Lee CM. Theoretical Prediction of motion of small waterplane area, twin-hull (swath) in waves, DTNSRDC report 76-004. Bethesda: 1976.
7. McCreight KK. Assessing the seaworthiness of SWATH ships. Transaction of SNAME. 1987; 95: 189-214.

8. Michalski JP. A parametric method for evaluation of resistance of swath ships. Pol Marit Res. 2008; 15: 3-10.

9. Bin Yakob O. Development of a Semi-SWATH craft for Malaysian waters. Research Vote No: 74204, Universiti Teknologi Malaysia, 2006.

10. Tamotsu N. Critical review of SWATH. Research Reports of Ikotoku Tech. Univ. B-11; 1987. 